\title{
Technique
}

\section{A rapid method of obtaining a jejunal biopsy using a Crosby capsule and a gastrointestinal fiberscope}

\section{B. J. PROUT From the Royal Cornwall Hospital (Treliske), Truro, Cornwall}

A method is described whereby a jejunal biopsy can be speedily obtained using a standard Crosby capsule (Crosby and Kugler, 1957) and a gastrointestinal fiberscope.

The main causes of delay in a time-consuming operation to obtain a jejunal biopsy is the time taken for the capsule to enter the pylorus and pass on through the duodenum. Techniques have consequently been developed in an effort to speed up the operation. In the method described by Wicks and Clain (1972) a guide wire is inserted down the tubing to allow control of the capsule and its manipulation through the pylorus under fluoroscopic control. The method of Evans, Farrow, Harding, and Stewart (1970) likewise uses a stiffening effect of an outer polythene sleeve around the biopsy tubing. In both these methods the patient is exposed to radiation whilst the pylorous is located and during subsequent corrective manipulations after the capsule turns up the greater curvature towards the fundus. Moreover when a wire is inserted it may be difficult to withdraw the wire from the tubing because of looping of the tube (Wicks and Clain, 1972). In the technique described here the patient is fasted in the usual manner and is then given an intravenous injection of diazepam (10-30 mg), the endpoint being determined clinically. An end-viewing gastrointestinal fiberscope is then inserted in the standard manner with the Crosby capsule arranged as follows:

The Crosby biopsy capsule is covered with a rubber jacket and radioopaque arterial catheter tubing is used (Salem, Salt, and Truelove, 1965). The tubing is inserted at the distal end of the biopsy channel of the gastrointestinal fiberscope and threaded through until it appears at the proximal end. The capsule is then pulled up until it rests on the distal end of the fiberscope. When the end-viewing GF type fiberscope is use the capsule fits neatly into the cupshaped end of this model and makes passage of the

Received for publication 28 March 1974. instrument actually easier than is usual when this type of instrument is used for routine endoscopy because the gullet is presented with a convex leading end.

When the fiberscope has been inserted the capsule can be advanced ahead of the fiberscope and this will allow inspection of the mucosa during passage of the combined fiberscope and capsule. The pylorus can rapidly be found and the fiberscope passed through with the capsule into the duodenum (fig 1). The fiberscope can be held in this position and the proximal end of the Crosby capsule tubing pushed onward towards the duodeno-jejunal flexure. In fig 2 the capsule has reached the second portion of the duodenum. The more rigid arterial tubing is particularly efficacious in this manoeuvre compared with the relatively flexible polythene tubing usually supplied with the Crosby capsule. Fluoroscopic control can be used to guide the capsule to the area for biopsy.

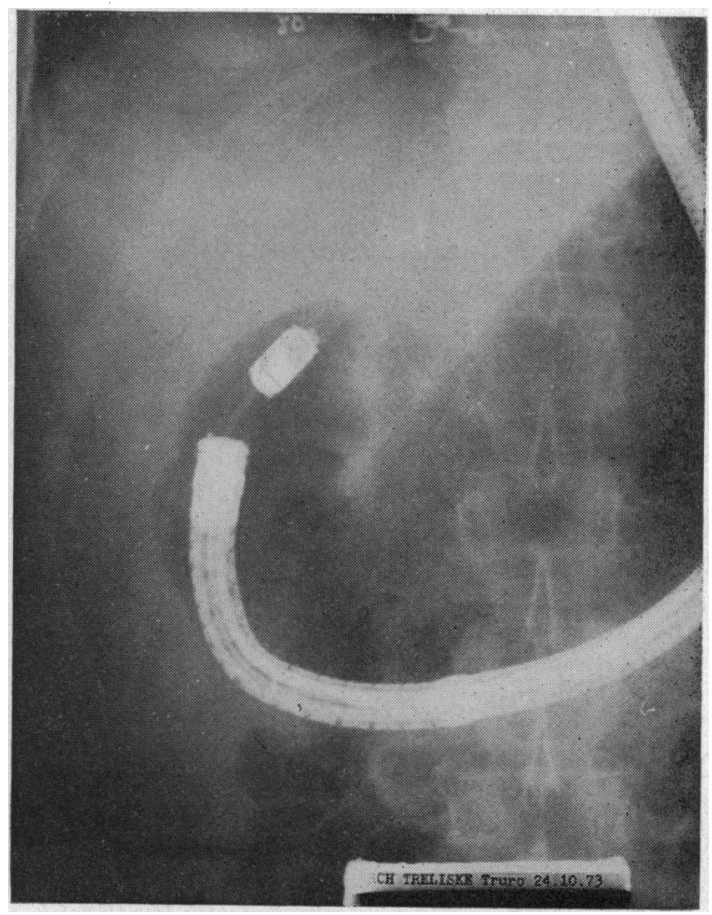

Fig 1 Straight radiograph of the abdomen with patient in the supine position showing the Crosby capsule in the pylorus and about to be introduced into the duodenum. 


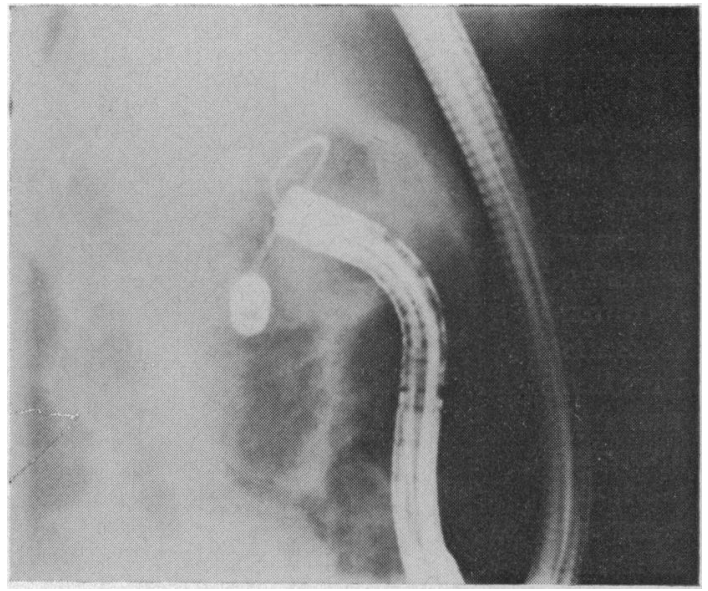

Fig 2 Lateral radiograph of the abdomen showing fiberscope in the second portion of the duodenum and the capsule is about to be advanced towards the third portion of the duodenum.

Figure 3 demonstrates the manoeuvrability of the technique. The technique has not only the advantage of speed but it is possible to carry out the entire procedure without the use of $x$ rays; the capsule and fiberscope can be introduced by direct vision into the junction of the second and third portions of the duodenum and then an appropriate length of capsule tubing advanced ahead of the fiberscope to the estimated region of the duodeno-jejunal flexure. Although the recently introduced fiberoptic enteroscope may have superseded this technique it is envisaged that this particular instrument will be used in a very limited number of centres (Classen, Frühmorgen, Koch, and Demling, 1972; Salmon, Brown, Burwood, and Read, 1973) whereas a standard gastrointestinal fiberscope may be found in an increasing number of district general hospitals.

Some 30 successful biopsies have been carried out by this technique each of them within five to 20 minutes of sedating the patient. Six patients have been successfully biopsied without the use of $x$ rays.

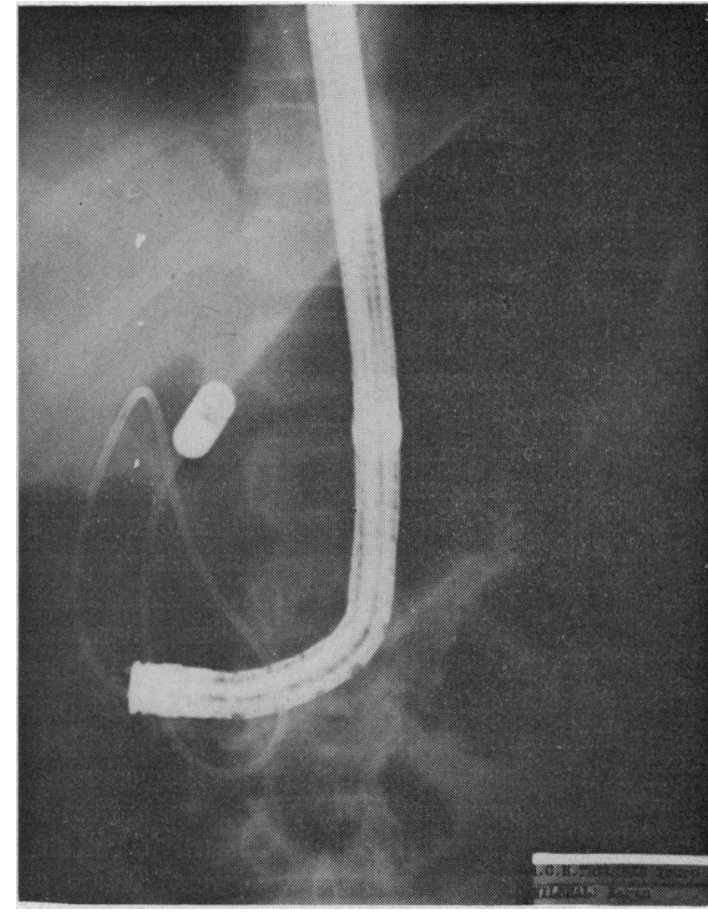

Fig 3 Straight radiograph of the abdomen after successful jejunal biopsy. To show the relative positions and the ease with which the two pieces of apparatus can be separately manoeuvred, the fiberscope has been withdrawn over the tubing of the Crosby capsule leaving the capsule in position. Both were then removed together.

\section{References}

Classen, M., Frühmorgen, P., Koch, H., and Demling, L. (1972). Enteroskopie Fiberendoskopie von jejunum and ileum. Dtsch. med. Wschr., 11, 409-411.

Crosby, W. H., and Kugler, H. W. (1957). Intraluminal biopsy of the small intestine: the intestinal biopsy capsule. Amer. J. dig. Dis., $2,236$.

Evans, N., Farrow, L. J., Harding, A., and Stewart, J. S. (1970). New techniques for speeding small intestinal biopsy. Gut, 11, 88-89.

Salem, S. N., Salt, R. H., and Truelove, S. C., (1965). Crosby small intestinal capsule with radio-opaque tube and latex sheath. Gut, 6, 99-100.

Salmon, P. R., Brown, P., Burwood, R., and Read, A. E. (1973). Examination of the duodenum and jejunum employing a new fiberoptic enteroscope. Gut, 14, 823.

Wicks, T., and Clain, D. (1972). A guide wire for rapid jejunal biopsies with the Crosby capsule. Gut, 13, 571. 